\title{
"Acá se sabe si la gente se aísla": (anti)anonimato, cuidado y poder en localidades medianas y pequeñas en tiempos de COVID-19
}

\section{"Aqui sabemos se as pessoas estão isoladas": (anti)anonimato, cuidado e poder em localidades pequenas e médias em tempos de COVID-19}

\section{"Here we know if people isolate themselves": (anti)anonymity, care and power in mid-sized and small towns in times of COVID-19}

\author{
(iD) Johana Kunin ${ }^{1}$ \\ Escuela Interdisciplinaria de Altos Estudios Sociales de la Universidad Nacional de San \\ Martín, Buenos Aires, Argentina \\ johanakunin@gmail.com \\ iD

\begin{abstract}
Yanina Faccio ${ }^{2}$
Escuela Interdisciplinaria de Altos Estudios Sociales de la Universidad Nacional de San Martín, Buenos Aires, Argentina yfaccio@gmail.com
\end{abstract}

Resumen: En el presente trabajo nos proponemos indagar en los modos a través de los cuales se ha gestionado la pandemia de enfermedad por coronavirus 2019 (COVID-19) en aglomeraciones medianas y pequeñas de la provincia de Buenos Aires (Argentina) en las que los vínculos “cara a cara" son predominantes. Nuestro material etnográfico se nutre de entrevistas a habitantes de distritos rurales bonaerenses en los que venimos haciendo trabajo de campo -presencial y ahora también a la distancia- desde hace ocho años, de notas periodísticas locales, y de

\footnotetext{
1 Becaria postdoctoral de Temas Estratégicos para el País del Consejo Nacional de Investigaciones Científicas y Técnicas de Argentina (CONICET), Buenos Aires, Argentina.

2 Becaria doctoral del CONICET, Buenos Aires, Argentina.
} 
audios y memes difundidos en redes sociales y servicios de mensajería instantánea vía teléfono celular. A partir del análisis de este corpus etnográfico, aquí presentamos dos hipótesis. En primer lugar, que, más allá de los tan mentados cambios radicales que ha traído la pandemia, los modos de gestionarla en tanto problema social a nivel cotidiano, al menos en las aglomeraciones de las escalas aquí tratadas, se han montado sobre mecanismos preexistentes, tales como la circulación de chismes y rumores -con frecuentes escaladas al escándalo, redes sociales de por medio. En segundo lugar, que, al mismo tiempo, no todo ha sido continuidad actualizada de repertorios sociales previos; a lo largo de la pandemia, hemos observado que situaciones de diferenciales de poder previamente "indecibles" han pasado a la esfera de lo denunciable; también, que han emergido nuevos repertorios -tales como el "auto-cuidado" o el "cuidado comunitario"- movilizados para justificar o incluso para demandar al Estado la circulación de información personal de reales o potenciales enfermos, puesto que émicamente se sostiene que saber quién está infectado puede evitar la transmisión del virus. Como veremos, en estos contextos particulares, la COVID-19 ha puesto en escena nuevos intersticios -o al menos la demanda de nuevas articulaciones- entre nociones de persona más o menos centradas en lo relacional o en el individuo, como modos de ejercer cuidados tanto sobre la salud comunitaria como sobre las reputaciones personales.

Palabras clave: COVID-19. Aglomeraciones medianas y pequeñas. Rumores. Cuidado. Poder.

Resumo: Esteestudo se propõe a investigar as maneiras como a pandemia de doença por coronavírus 2019 (COVID-19) tem sido gerida em pequenas e médias aglomerações na província de Buenos Aires (Argentina) onde as relações "face a face" são predominantes. Nosso material etnográfico se baseia em entrevistas com habitantes de distritos rurais portenhos onde temos realizado trabalho de campo - presencial e agora também a distância - nos últimos oito anos, por meio de reportagens de jornais locais, além de áudios e memes compartilhados em redes sociais e serviços de mensagens instantâneas via telefone celular. Partindo da análise desse corpus etnográfico, apresentamos aqui duas hipóteses. 
Em primeiro lugar, que, para além das muito faladas mudanças radicais decorrentes da pandemia, as maneiras de geri-la enquanto "problema social" em nível cotidiano, pelo menos em aglomerações nas escalas aqui abordadas, foram organizadas em mecanismos sociais pré-existentes, como a circulação de fofocas e rumores - com frequentes escaladas para o escândalo, tendo as redes sociais como meio. Em segundo lugar, que, ao mesmo tempo, nem tudo tem constituído uma continuidade atualizada de repertórios sociais anteriores; ao longo da pandemia, observamos que situações com diferenciais de poder anteriormente "indizíveis" passaram à esfera do "denunciável"; ademais, que surgiram novos repertórios - como o "autocuidado" ou o "cuidado comunitário" - mobilizados para justificar ou até exigir do Estado a circulação de informações pessoais de pacientes reais ou potenciais, uma vez que se entende emicamente que saber quem está infectado pode evitar a transmissão do vírus. Como veremos, nesses contextos específicos, a COVID-19 criou novos interstícios - ou, pelo menos, a busca por novas articulações - entre noções de pessoa mais ou menos centradas no relacional ou no indivíduo, como maneiras de proporcionar cuidados tanto no âmbito da saúde comunitária quanto no das reputações pessoais.

Palavras-chave: COVID-19. Médias e pequenas aglomerações. Rumores. Cuidado. Poder.

Abstract: The present paper aims to investigate the ways in which the coronavirus disease 2019 (COVID-19) pandemic has been managed in mid-sized and small agglomerations in the province of Buenos Aires (Argentina) where 'face-to-face' relationships are predominant. Our ethnographic material draws on interviews with inhabitants of rural districts in Buenos Aires where we have been conducting fieldwork face-to-face and now also non-face-to-face - for eight years, by means of local newspaper coverage, as well as audios and memes shared on social media and mobile phone instant messaging services. Having the analysis of this ethnographic corpus as a basis, we present herein two hypotheses. First that, beyond the much talked about radical changes caused by the pandemic, the ways of managing it as a social issue at a daily life level, at 
least in the agglomeration sizes discussed herein, have been organized into pre-existing mechanisms, such as the circulation of gossip and rumors - frequently escalating into scandal, relying on social media as a means. Second that, at the same time, not everything has been an updated continuity of previous social repertoires; throughout the pandemic, we have observed that situations involving power differentials that were previously 'unspeakable' entered the whistleblowing sphere; also, that new repertoires have emerged - such as 'self-care' or 'community care' - as mobilized to justify or even require from the State the circulation of personal information of real or potential patients, since it is emically understood that knowing who is infected can prevent virus transmission. As we will see, in these particular contexts, the COVID-19 has opened new interstices - or, at least, the social requirement for new connections - between concepts of person more or less focused on the relational sphere or on the individual, as ways of caring for both community health and personal reputations.

Keywords: COVID-19. Mid-sized and small agglomerations. Rumors. Care. Power.

4

Data de recebimento: 09/10/2020

Data de aprovação: 02/02/2021 
“Acá se sabe si la gente se aísla": (anti)anonimato, cuidado y poder en localidades medianas... Johana Kunin • Yanina Faccio

\section{Introducción}

El 20 de marzo de 2020, el gobierno nacional argentino decretó el aislamiento social y obligatorio en todo el país como medida para controlar los contagios por enfermedad por coronavirus 2019 (COVID-19). Poco más de un mes después, en abril, se abrió la posibilidad de que los gobiernos provinciales habilitaran, según cada situación epidemiológica particular, la circulación de personas que realizaban "determinadas actividades y servicios" (ARGENTINA, 2020) bajo el cumplimiento de los debidos protocolos. Así, las provincias argentinas e incluso distintos municipios al interior de cada una de ellas quedaron en diferentes fases de la cuarentena. Si bien en un comienzo la mayor parte de los casos de COVID-19 se dieron en ciudades de gran envergadura y entre personas venidas del exterior del país, los contagios pronto empezaron a ocurrir también en localidades de menor porte y a producirse por vía comunitaria. En este artículo, indagamos los modos en los que la pandemia se ha gestionado, tanto de manera oficial como informal, en distritos pequeños y medianos de la provincia de Buenos Aires. Como veremos, allí la COVID-19 ha puesto en marcha mecanismos sociales ordinarios, tales como la circulación de chismes y rumores y su eventual escalada al escándalo. Estos, al mismo tiempo, han proliferado a nivel tal que han llevado a la emergencia de situaciones que consideramos "extraordinarias" en las que, en nombre del cuidado, se ha vuelto posible denunciar a quienes antes eran "indenunciables" o demandar al Estado que "desanonimice" sus comunicados oficiales acerca del estado de la pandemia a nivel local.

Los distritos que nos sirven aquí de base empírica pueden ser definidos como "agrociudades", esto es, nucleamientos urbanos de tamaño medio localizados en territorios eminentemente dedicados a la agroindustria, en la cual se origina una buena parte del producto bruto interno local y nacional. En estos contextos, la agrociudad es el centro en torno al cual se articula tanto la actividad agropecuaria como el resto de los sectores productivos 
“Acá se sabe si la gente se aísla": (anti)anonimato, cuidado y poder en localidades medianas... Johana Kunin • Yanina Faccio

y de servicios (industriales, administrativos, judiciales, etc.) que organizan la dinámica del territorio, y a su alrededor generalmente hay varias aglomeraciones pequeñas, cuya población suele oscilar entre los 1.000 y los 100 habitantes (ALBALADEJO, 2013).

La sociabilidad típica de estos agro-distritos medianos y pequeños se caracteriza por el peso sociopolítico fuerte que en ellos tienen los actores agropecuarios notables para la toma de decisiones, por la importancia de la institución familiar para la cohesión y la integración social y por el conocimiento mutuo entre sus habitantes (ALBALADEJO, 2013). Se trata de localidades en las que dominan las tramas sociales propias del "contexto pequeño urbano" (BLANC, 2016, nuestra traducción). Con Koury y Barbosa (2017, p. 22, nuestra traducción), entendemos que la sociabilidad de este tipo de aglomeración no puede ser conceptualizada "como una caricatura a pequeña escala de la metrópoli, pero como una sociabilidad específica que plantea preguntas propias". Dadas las proporciones demográficas y la densidad de los vínculos entre sus habitantes, en ellas existe un fuerte conocimiento o al menos "reconocimiento" (PRADO, 1998) mutuo entre co-residentes, quienes suelen encuadrar a los demás y a ser encuadrados por ellos a partir de largas "cadenas de reputación" (BLANC, 2016) que frecuentemente se remontan a eventos y a relaciones históricas entre personas y familias. El corolario de este fenómeno es la gran dificultad que tienen sus habitantes para erigirse como "anónimos". En efecto, las personas suelen saber quiénes son los otros, a qué familia pertenecen y a qué se dedican, aunque sea de manera aproximada. Durante nuestros trabajos de campo más de una vez hemos escuchado frases como: "acá sos y portás todo el antecedente de tu familia" o "si discutís con una persona aquí, discutís con quince" (KUNIN, 2019). En la provincia de Buenos Aires se corrobora, entonces, lo que Prado (1998, p. 50, nuestra traducción) plantea para el "pequeño urbano" brasileño, a saber, que el mutuo conocimiento allí preponderante suele ser experimentado por sus habitantes como, por un lado, una suerte de "espejo acogedor" -en tanto "todos saben quién soy"- $y$, por 
"Acá se sabe si la gente se aísla": (anti)anonimato, cuidado y poder en localidades medianas... Johana Kunin • Yanina Faccio

otro, como una estructura controladora y constreñidora de la personalidad -en tanto "todos saben lo que hago".

La pandemia ha implicado, en núcleos poblacionales de todo tipo de escala, una situación de crisis signada por la incertidumbre en cuanto a la vida cotidiana contemporánea y al futuro (VISACOVSKY, 2019, 2020). A todo nivel, la COVID-19 se ha traducido en hechos y experiencias concretas: las muertes, la proliferación de personas enfermas y "contagiosas" y la adopción de reglas y restricciones sociales inéditas en cuanto al comportamiento y a la circulación públicos. La pandemia puede ser entendida como un acontecimiento extraordinario o, en términos de Koury y Barbosa (2017, p. 29, nuestra traducción), "traumático", en tanto ha implicado una "ruptura de la normalidad normativa y desorientación de expectativas que desencadenan situaciones límite sobre la fragilidad de la vida o de procesos sociales más amplios, generando vulnerabilidades y búsqueda de reacomodo de los horizontes morales locales". En relación con ello, algunas de las inquietudes que orientan este artículo son las siguientes: ¿Cómo se encuadra y gestiona, a nivel local, la situación epidemiológica entendida como un evento extraordinario?; ¿Qué rasgos toma esta gestión desde los niveles estatales y burocráticos; ¿Qué rasgos toma "desde abajo" -es decir, desde lo que podríamos identificar, retomando a Pitt-Rivers (1989), como "el pueblo"?; ¿Cuáles son sus efectos en las micropolíticas de las relaciones sociales en el marco de estas pequeñas y medianas localidades?; y ¿Qué continuidades y qué emergencias encontramos en comparación con dinámicas previas?

A partir de la exposición de un conjunto de escenas etnográficas, intentaremos mostrar, en primer lugar, que la gestión de la pandemia se monta, por un lado, sobre mecanismos preexistentes y omnipresentes en este tipo de localidad (HAGENE, 2010; KOURY y BARBOSA, 2017; PITT-RIVERS, 1989), tales como el chisme, el rumor y eventuales escándalos, de modo tal que prácticas ordinarias de control social terminan por ordenar o al menos volver un poco más inteligible la vida social en tiempos extraordinarios. En segundo lugar, las propias escenas etnográficas también nos llevarán a ver 
“Acá se sabe si la gente se aísla": (anti)anonimato, cuidado y poder en localidades medianas... Johana Kunin • Yanina Faccio

Las fuentes de este artículo son conversaciones informales por canales de mensajería instantánea con informantes ya conocidos de nuestros años de trabajo de campo, así como con personas que hemos contactado a través de la técnica de la "bola de nieve". También, la recuperación de textos, audios de WhatsApp -en los que circulan chismes, rumores, escándalos y denuncias- y memes que se viralizaron en las zonas en las que trabajamos y que, en ocasiones, llegaron a trascender las escalas locales. En relación con este tipo de material, nuestros informantes también nos proveyeron de audios y memes ligados a escándalos surgidos en otras localidades de escalas similares, pero que circularon de todos modos por las suyas "haciendo espejo" con la propia situación de cuarentena. Asimismo, observamos comportamientos, repertorios y demandas a los gobiernos municipales, emergentes en Facebook y en medios de comunicación locales. El presente artículo se configura, entonces, en un sentido metodológico y también en un sentido temático -ya que trata el tema de la pandemia que, por imprevisto, no formaba parte de nuestra agenda de investigacióncomo un "ejercicio antropológico de emergencia" (PIZARRO y MATTA, 2020).

En cuanto a una de las áreas que tocamos en gran parte de este escrito, es decir, la relación entre chismes, rumores, escándalos y salud, podemos destacar distintos antecedentes. Entre ellos, se cuentan los trabajos que abordan la relación entre rumores, sospechas y teorías conspirativas a niveles locales y globales, por ejemplo, para los casos de las vacunas en Camerún (FELDMANSAVELSBERG, NDONKO y YANG, 2017), o para el SIDA (NIEHAUS y JONSSON, 2005) o la polio (RENNE, 2010), ambos en Nigeria. Por otra parte, podemos destacar que enfermedades infecciosas como el SIDA han sido estudiadas para identificar diferentes mecanismos de culpabilización de los contagiados (GILMAN, 1991) y la emergencia de pánicos morales en los que los actores relacionan dicha dolencia con prácticas de brujería (DAHL, 2012; STADLER, 2003). Otros antecedentes son aquellos que indagan en la discriminación que sufren quienes contraen el virus (BRIGGS, 2005; PARKER, 2001; ROOT, 2010; SCHOEPF, 2001). 
“Acá se sabe si la gente se aísla": (anti)anonimato, cuidado y poder en localidades medianas... Johana Kunin • Yanina Faccio

Por otra parte, numerosos antropólogos han investigado emergencias sanitarias tales como la del ébola (ABRAMOWITZ, 2014; KUTALEK et al., 2015; MARTINEAU, WILKINSON y PARKER, 2017; VENABLES y PELLECCHIA 2017). En tiempos recientes, los contagios por el virus del Zika han sido estudiados por las ciencias sociales. Diniz (2016), por ejemplo, analizó las narrativas de nordestinos brasileños que experimentaron la epidemia en sus cuerpos y el modo en el que desconfiaban de las explicaciones oficiales. Stalcup (2020), por su parte, define al caso del Zika como una "infodemia" en la que circularon grandes caudales de información falsa por audios de WhatsApp.

Para el caso específico de la COVID-19, a nivel internacional se han estudiado los rumores en calidad de fake news y de teorías conspirativas a escala global (ALI, 2020; KUNJANA, 2020; SUBEDI, THAPA y PANDEY, 2020). Benson (2020), por ejemplo, observa el modo en el que, en Sudán, el virus es interpretado como parte de una guerra económica entre China y Estados Unidos (EE.UU.). También se han analizado los casos de discriminación y rumores que trajo la pandemia entre habitantes de distintos países y la manera en la que ciertas nacionalidades fueron consideradas como las culpables de su propagación (PELLEGRINO, 2020). En varios casos, sobre todo por fuera de la literatura antropológica, los rumores son entendidos como un obstáculo para la comunicación sanitaria y como creadores de pánico y ansiedad (SAADAT et al., 2020), en lugar de como prácticas políticas sociales y habituales en los grupos humanos.

Desde Argentina, por su parte, Pizarro y Matta (2020, p. 4) han hecho unvalioso relevamiento aescala nacional decasos de"escrache, estigmatización, acoso y amenazas a personas sospechadas o confirmadas de COVID-19", marco en el cual la categoría de "vecino" se perfila como un emergente y como una arena de conflicto. Nuestra propuesta, por su parte, también se vincula con el análisis de la gestión de conflictos, intentando mantener el foco etnográfico sobre las prácticas políticas del rumor y del escándalo a escala local. Desde nuestra perspectiva antropológica, no hay nada de fake en lo 
“Acá se sabe si la gente se aísla": (anti)anonimato, cuidado y poder en localidades medianas... Johana Kunin • Yanina Faccio

que circula: los chismes y las acusaciones son una ventana para ver lo social y sus desigualdades en continua renovación en tiempos de COVID-19.

\title{
“Individuos" para el Estado, "personas" para "el pueblo"
}

\author{
"Acá nos conocemos entre todos; sabemos quién hace la cuarentena y \\ quién no la hace." \\ Estela (33 años, horticultura familiar)
}

Apenas comenzaron a proliferar los casos de COVID-19, los gobiernos municipales de los distritos aquí explorados tomaron un conjunto de medidas en relación, por un lado, con las infraestructuras sanitarias (el equipamiento de los hospitales públicos, por ejemplo) y, por otro, con el orden de la prevención. Se estableció la obligatoriedad de la cuarentena en distintas fases -según la evolución de la situación epidemiológica de cada municipio- y se implementaron campañas de comunicación en vistas a explicar cuál era la sintomatología de la COVID-19, qué medidas debían tomarse ante las sospechas de padecerlo, cómo se prevenían los contagios y cuáles eran los modos correctos de hacer la cuarentena. También, comenzaron a circular reportes diarios con información cuantitativa acerca del estado de la pandemia en cada distrito, incluyendo la cantidad de personas en tratamiento por la enfermedad, de casos confirmados, de recuperados y de fallecidos.

Estas comunicaciones se suelen realizar en la vía pública -a través de cartelería-, en los medios locales -desde las propias tapas de los diarios- y de los sitios web, de Facebook e Instagram de los gobiernos municipales. Se trata de informes que imitan el estilo de los que, a mayor escala, hace el Ministerio de Salud de la Nación a diario, y que ofrecen información local, oficial, técnica y cuantitativa. Día a día, las cifras que publica el gobierno municipal permiten entender las dimensiones de la pandemia asegurando 
"Acá se sabe si la gente se aísla": (anti)anonimato, cuidado y poder en localidades medianas... Johana Kunin • Yanina Faccio

el anonimato de las personas que se esconden detrás de los números. Sin embargo, al nivel del "pueblo" (PITT-RIVERS, 1989) es otro el tipo y el tono de la información que circula. Es un ejemplo de ello una lista con supuestos contagiados ${ }^{3}$, que se divulgó informal y viralmente vía WhatsApp en julio de 2020 en una de las ciudades medianas en las que trabajamos (Figura 1).

Figura 1. Lista con supuestos infectados que circuló por WhatsApp ${ }^{4,5}$

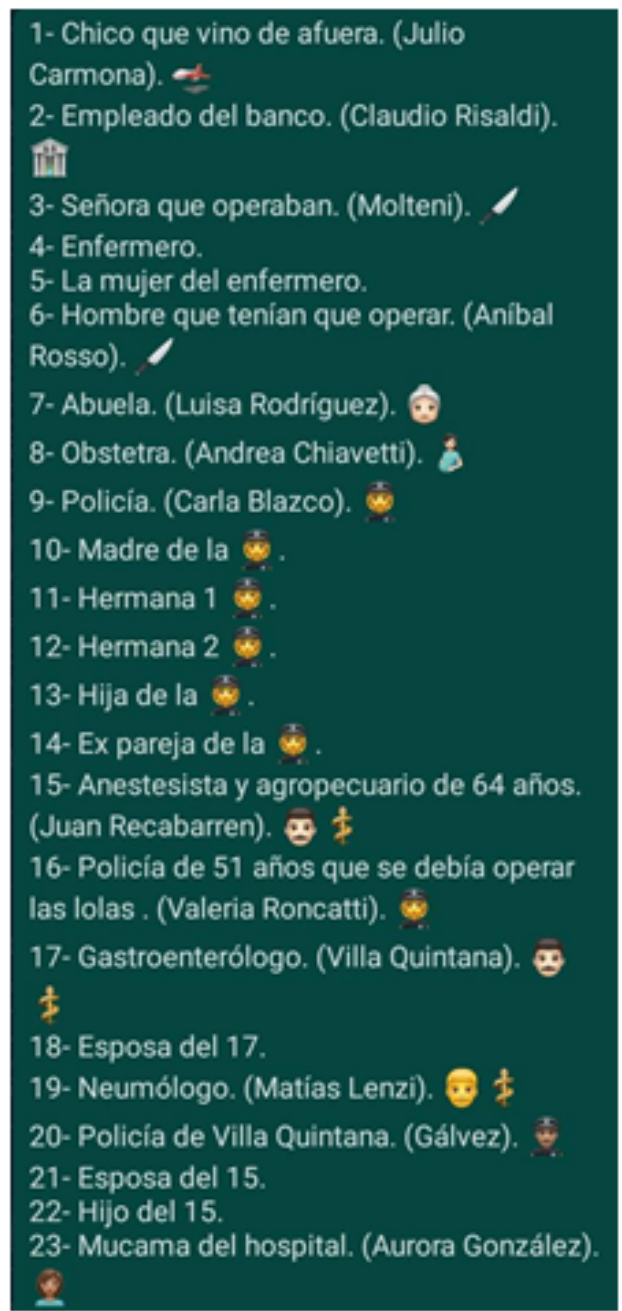

1- Chico que vino de afuera. (Julio

Carmona). $\Rightarrow$

2- Empleado del banco. (Claudio Risaldi).

3- Señora que operaban. (Molteni)

6- Hombre que tenian que operar. (Aníbal Rosso)

7-Abuela. (Luisa Rodriguez). 2

8- Obstetra. (Andrea Chiavetti).

9- Policía. (Carla Blazco).

10- Madre de la \&

1 -Hermana $1 \&$

12- Hermana 2 .

13- Hija de la $\$$

14- Ex pareja de la $\bar{\epsilon}$.

15- Anestesista y agropecuario de 64 años.

(Juan Recabarren). $\bar{z} \frac{\dot{z}}{\mathbf{z}}$

16- Policia de 51 años que se debia operar

17- Gastroenterólogo. (Villa Quintana).

18- Esposa del 17.

19- Neumólogo. (Matias Lenzi). 7

20- Policía de Villa Quintana. (Gálvez),

21- Esposa del 15.

a

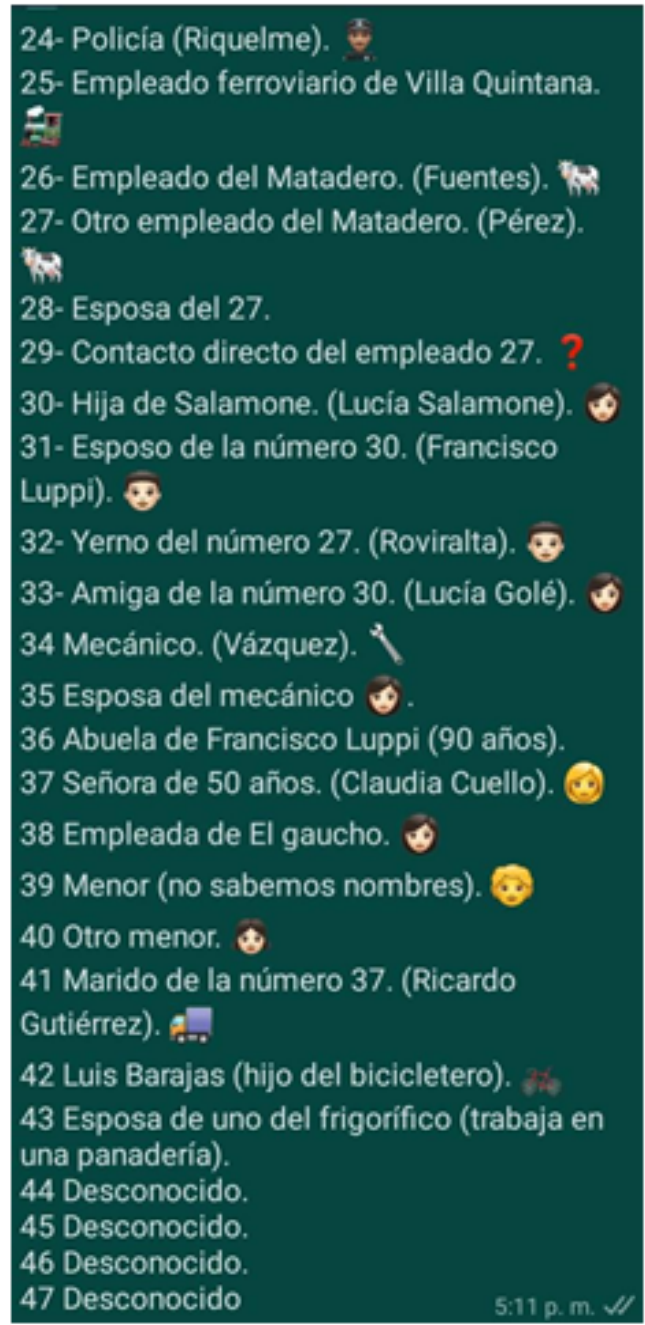

Fuente: Colección personal de las autoras.

3 Por motivos de confidencialidad, hemos reemplazado en todo el trabajo los nombres reales de lugares y personas por pseudónimos.

4 Los nombres propios en estas imágenes fueron retocados digitalmente para preservar el anonimato de nuestros informantes. 5 En el número 16 de esta lista se usa la expresión operarse las "lolas" - quiere decir "hacerse una cirugía estética mamaria". 
“Acá se sabe si la gente se aísla": (anti)anonimato, cuidado y poder en localidades medianas... Johana Kunin • Yanina Faccio

Nuestros informantes dicen sospechar quién pudo haber sido la persona que confeccionó esta lista, aunque -siguiendo una lógica muy común del rumor- no han precisado nombres. Cuando les preguntamos qué pensaban de que circularan estos datos, algunos de ellos nos dijeron que, quien fuera que los hubiera compilado estaba haciendo, en última instancia, lo mismo que hacía el Estado, a saber, controlar los casos de COVID-19 para ejercer un cuidado de la ciudadanía.

Ahora bien, es evidente que la información que este mensaje de WhatsApp provee satura con creces a la ofrecida por la esfera municipal, en tanto en él se ponen a disposición nombres, apellidos e información vincular específica para, en el caso de no reconocer la "cara" de la persona contagiada, lograr, de todos modos, ubicarla a partir de sus relaciones sociales: ser "hijo de", "amiga de", "esposo de" o "trabajadora en". Podríamos decir que si el gobierno municipal habla el lenguaje moderno y burocrático de las instituciones, en las que todas las personas son "individuos" iguales ante la ley $-\mathrm{y}$, por lo tanto, pasibles de ser contabilizados (DAMATTA, 1985, 2002)-, en la lista confeccionada manualmente por este misterioso gossiper (PAINE, 1967) se pone en evidencia la noción relacional de persona que impregna la vida del pequeño y mediano urbano (PRADO, 1998): una en la que cada habitante se define no solo por ser quien es, sino también por su posicionamiento en una red vincular de gran densidad en la que se encuentran inscriptas historias previas y relaciones de jerarquía.

En línea con este mensaje escrito, circularon audios de WhatsApp en los que un chisme que inicialmente iba dirigido a un receptor dado luego se viralizaba más allá del entorno íntimo, divulgando la identidad de los afectados, en algunos casos más allá de los límites locales:

\section{Audio 1}

[El infectado], creo, es hijo de la Chocha Perotti. Vive ahí en el barrio San Martín. Se fue a lo de la madre, a lo de Chocha. La madre que le alquila un cuarto a Pichi Lisanti. Y la Chocha viste 
“Acá se sabe si la gente se aísla": (anti)anonimato, cuidado y poder en localidades medianas... Johana Kunin • Yanina Faccio

que es medio curandera, media bruja. Y yo me enteré de esto por mi hermana. Que dice que viene mucha gente a la casa de la vieja, a cada rato, en remís 6 . Dicen que puede ser por eso, por la gente que viene, que se lo agarró ahí.

\section{Audio 2}

[El infectado] es hijo de Chocha Perotti. Después te cuento la historia de la familia, que se juntaron por el cumpleaños de la Romina Perotti. Incluido Pepo, Tota, la Pochola, la chica de Cosme que trabaja en la esquina de la Municipalidad. El Toto es el que trabaja en la casa del Cosme, que vive con la Pochola. Y vive con la hija de Coqui y vive con el nenito ${ }^{7}$. Todo un quilombo ${ }^{8}$. Así que estamos al horno con papas ${ }^{9}$.

En estos dos audios enviados por una misma mujer, se brindan detalles acerca de la identidad de uno de los primeros infectados por COVID-19 en su localidad de residencia. En ellos, nuevamente vemos cómo circulan no solo el nombre del contagiado y sus allegados, sino también distintas informaciones que aseguran el correcto encuadramiento de sus identidades: relaciones de parentesco ("hijo de Chocha"), de residencia ("Cosme, que vive con la Pochola"), laborales ("la chica que trabaja en la Municipalidad") o geográficas ("Vive ahí en el barrio San Martín). De este modo, se devela no solo quién padece el virus, sino también sus posibles vías de contagio (por ejemplo, la madre curandera que recibe pacientes "de afuera", posibles transmisores de la enfermedad) y los contactos estrechos que podrían seguir difuminando la -en términos nativos- "peste". En este punto, se vuelve evidente que la gestión de la pandemia "desde abajo" implica ciertas continuidades de mecanismos ordinarios preexistentes, como la reactivación de redes de conocimiento mutuo y la transmisión de información por vía de chismes y el rumor, que siempre han estado presentes. Todo lo que el Estado calla en pro de la protección de la privacidad del

\footnotetext{
6 En Argentina, un "remís" es un auto con conductor cuyo servicio se paga por kilometraje realizado, muy frecuente en aquellas localidades donde no hay taxis circulando en la vía pública.

7 "Nenito" es el diminutivo de la palabra "nene", equivalente familiar a "niño" en Argentina.

8 En Argentina, la palabra "quilombo" se utiliza para hacer referencia a un lugar o situación desordenada y confusa.

9 En Argentina, la locución "estar al horno con papas" significa "estar en una situación grave o complicada".
} 
“Acá se sabe si la gente se aísla": (anti)anonimato, cuidado y poder en localidades medianas... Johana Kunin • Yanina Faccio

individuo, circula por la red de "control social informal" (HAGENE, 2010; MERRY, 1997) "pública, discreta, y no secreta" (KOURY y BARBOSA, 2017, p. 13-14) del chisme.

En un texto clásico acerca de esta temática, Paine (1967, p. 283, nuestra traducción) sugiere que los rumores son un tipo de comunicación que contribuye a "dar forma a temas vagos o confusamente percibidos por una población local". A partir de este insight, podemos pensar que la circulación de información a través del rumor puede contribuir a la difusión de ciertos temas de preocupación públicay a, con el correr de las repeticiones, darles una forma cada vez más delimitada. En línea con esta sugerencia, Koury y Barbosa (2017) sostienen que el rumor se constituye como un modo a través del cual acontecimientos nuevos y traumáticos -ellos trabajan, por ejemplo, el caso de un accidente vial en una localidad pequeña- se interpretan y se estabilizan públicamente, volviéndose pasibles de ser reincorporados a la vida normal. Los chismes son, para estos autores, "una forma de reensamblar el hecho en un nuevo formato posible desde el cual procedery reorganizar la vida ordinaria en una pequeña ciudad" (KOURY y BARBOSA, 2017, p. 24, nuestra traducción). Así, aquí proponemos que en contextos signados por la irrupción de un hecho absolutamente novedoso como la pandemia, que implica altos niveles de incertidumbre social, la red de chismes y rumores reencausa el acontecimiento y lo ordena para, al menos, darle dimensiones conocidas y ordinarias al anclarlo en personas claramente identificables y en eventos concretos y reconocibles.

Por otra parte, tal como lo ha señalado repetidas veces la literatura antropológica, el chisme y el rumor no solo "ordenan" ideas, sino que, sobre todo, se configuran como expresiones de control social (ELIAS y SCOTSON, 2000; FONSECA, 2000; GLUCKMAN, 1963; HAGENE, 2010; MERRY, 1997; PITT-RIVERS, 1989). La discreción inherente a los rumores permite "informar sin denunciar" $y$ "protege los secretos y separa a las audiencias de situaciones embarazosas de posible pérdida de prestigio y escándalo" (KOURY y BARBOSA, 2017, p. 30, nuestra traducción). En este sentido, los textos y audios de WhatsApp que transcribimos más arriba no solo dan cuenta de la 
"Acá se sabe si la gente se aísla": (anti)anonimato, cuidado y poder en localidades medianas... Johana Kunin • Yanina Faccio

supuesta identidad de los infectados por COVID-19, sino también de la de sus contactos estrechos, poniendo en evidencia, por ejemplo, una violación de la cuarentena durante un festejo de cumpleaños. Como nos decía una de nuestras interlocutoras, docente rural: "acá nos conocemos todos; sabemos quién hace la cuarentena y quién no la hace".

Una de las principales potencias del chisme en general es que regula comportamientos sin llegar a una confrontación abierta que podría afectar más radicalmente reputaciones personales o grupales, generar conflictos públicos o implicar la movilización de la justicia formal. En épocas de pandemia, los chismes contribuyen a que las personas mantengan las violaciones de cuarentena "a raya" o, por lo menos, a que las lleven a cabo de manera discreta. A continuación, sin embargo, veremos que la línea que separa al chisme del escándalo abierto o la denuncia es, en estos tiempos, más fina que de costumbre.

\title{
El escándalo viralizado y mediatizado
}

\author{
"Yo cuidándome toda y estas mugres apestándose ahí en el boliche ${ }^{10} . "$ \\ Audio viralizado en el que una madre habla sobre sus hijos (que \\ violaron la cuarentena en un bar de campo)
}

Un domingo de agosto por la noche, un grupo de más de 30 personas hizo una reunión social en una pulpería, espacio de sociabilidad propio de las regiones rurales de distritos como los que aquí exploramos. Durante el evento, uno de los asistentes grabó un video con su celular y se lo envió a un amigo.

El video dura 35 segundos y es una especie de plano secuencia. En primer lugar, se puede ver el rústico "boliche" o bar de campo, con sus puertas y muebles de madera y su decoración típicamente

10 "Mugre" es un sinónimo coloquial del vocablo "suciedad". En este caso, la enunciadora usa la palabra "mugre", fuertemente despectiva, para referirse metafóricamente a sus hijos, queriendo decir que son gente de poco valor. 
“Acá se sabe si la gente se aísla": (anti)anonimato, cuidado y poder en localidades medianas... Johana Kunin • Yanina Faccio

"campera", con espuelas y cintos adornando las paredes. Junto a la puerta de entrada, un hombre de unos 60 años, vistiendo pantalones y botas de campo sencillos, toca el acordeón. Al lado de él, un grupo de mujeres sentadas en sillas dispuestas en forma de "u" conversan y lo miran. Luego, la cámara del celular sigue su camino y filma el mostrador del bar, antiguo, pesado, de madera y pintado de azul. Sobre la barra, se ve una botella de vino y una de cerveza, un vaso de fernet -aperitivo italiano muy común en Argentina - y un atado de cigarrillos. Detrás del mostrador, 7 hombres conversan; 5 de ellos con las boinas típicas del atuendo campero, aunque vestidos sencillamente, no como si fuera un día de fiesta. La cámara del celular sigue su recorrido y hacen aparición los estantes de la barra, llenos de botellas de distintas bebidas alcohólicas, y 5 hombres más conversando. Algunos están sentados en la barra y otros están detrás, atendiéndola. En los segundos finales del video, el celular enfoca la cara de un hombre de unos 40 años, de barba, boina, camisa, chaleco y pañuelo al cuello -es decir, con todo el atuendo campero- que, mirando a la cámara, levanta un chop de cerveza y lanza un animado "sapukay", que es el grito que se hace durante los solos de acordeón de chamamé, ritmo folklórico típico del nordeste argentino. Finalmente, el dueño del celular, en modo selfie, se filma a sí mismo -es un hombre de mediana edad con sombrero de gaucho- que, con mirada pícara y tonada "de campo", dice "iestamos todo" acá!", tras lo cual vuelve a hacer una panorámica veloz de la pulpería, mostrando rápidamente a todos los asistentes.

Podría ser una escena de una fiesta en un pequeño pueblo agrario bonaerense del verano de 2005 , de la primavera de 2013 o del invierno de 2017, si no fuera porque fue filmada en 2020 en plena pandemia. Aunque para esa época el municipio donde se emplazaba la pulpería se encontraba en la fase 5 de la cuarentena -el estadio más laxo del distanciamiento social-, las reuniones con tal cantidad de personas en espacios cerrados no estaban permitidas. Si bien los vecinos se quejaron con la policía por los ruidos provenientes desde adentro del local, los agentes 
“Acá se sabe si la gente se aísla": (anti)anonimato, cuidado y poder en localidades medianas... Johana Kunin • Yanina Faccio

llegaron durante la madrugada, momento para el cual el grupo de asistentes estaba disperso, y no prendieron a nadie. No hubo, por lo tanto, una aplicación de sanciones legales por vía oficial contra los participantes del evento, ni esa noche ni a la mañana siguiente, cuando sus identidades ya eran vox populi. Para el lunes, en efecto, el video se había viralizado junto con los audios de la madre de dos de los presentes en la pulpería, quien se expresaba de la siguiente manera:

\section{Audio 3}

Mirá, qué hijos de puta... El que está apoyado en el mostrador de barba es mi hijo, Manuel. El que grita y levanta la copa es Lalo Costa, de Villa Quintana. El otro que se tapa la cara no lo puedo ubicar. El otro que grita es Emilio Vázquez. Después, Agustín Ratier. Y el que está sentado abajo es Miguel, mi otro hijo. Hasta Camila había ido. Lo que pasa es que fue el cumpleaños de mi cuñado y después se fueron todos a mamar ${ }^{11}$ ahí. No sabés la bronca que me agarró el domingo. No podía dormir. Me subió la presión. Los cagué a puteadas ${ }^{12}$. Los eché a todos a la mierda. Yo cuidándome toda y estas mugres apestándose ahí en el boliche.

Por si no quedaban dudas, al video original se le sumaban, gracias a esta elocución, las indicaciones con nombre y seña de todos los presentes. De más está decir que al interior del distrito donde ocurrió el evento, dichas indicaciones orales no eran necesarias en tanto los que estaban en la pulpería, en palabras de una interlocutora local, "era toda gente conocida de las fiestas de campo de ahi". En un lapso de menos de veinticuatro horas, el material audiovisual casero circuló por la localidad, por sus distritos vecinos $y$, finalmente, por distintos medios de comunicación nacionales. En uno de estos últimos, televisivo, el video fue difundido con el hashtag \#indignante y bajo el título de "Escándalo por una fiesta en una pulpería". Así, una producción casera y local fue recontextualizada a escala nacional como un exemplum moral

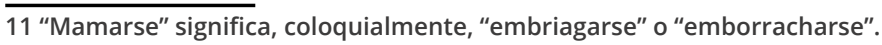

12 “Cagar a puteadas" es una expresión fuertemente coloquial que significa "reprender" o, en portugués, xingar. 
“Acá se sabe si la gente se aísla": (anti)anonimato, cuidado y poder en localidades medianas... Johana Kunin • Yanina Faccio

acerca de lo que "no se debe hacer durante la cuarentena". Los participantes no solo fueron "mugres apestándose" insertos en una fuerte red relacional local que los conocía y los controlaba, sino también personajes de una fábula nacional destinada a exhibir ciertas prácticas como inaceptables en tiempos de COVID-1913.

En este caso, nos enfrentamos con una situación cuyo recuento podría haber quedado en chisme pero que, en gran parte gracias a las redes sociales, escaló rápidamente hasta convertirse en un escándalo abierto, entendido como un proceso social en el cual situaciones y dichos que hasta cierto punto eran tolerables se vuelven, por su gravedad o por las dimensiones que alcanzan, imposibles de "negación pública y formal" (KOURY y BARBOSA, 2017, p. 36, nuestra traducción). La bibliografía señala que los escándalos suelen tener consecuencias para los implicados, generalmente bajo distintas formas de sanción social, tales como “apodos, burla, canciones degradantes, ostracismo, acusaciones de brujería, expulsión, muerte social y hasta física" (MERRY, 1997, p. 60-61). En este caso -ocurrido en el seno de una "sociedad hipermediatizada" (CARLÓN, 2015) en la que los medios masivos e internet se articulan de manera compleja-, podríamos decir que los implicados sufrieron, como principal sanción, la divulgación de sus "caras" a escalas bien mayores a las esperables en circunstancias ordinarias -situación que hemos registrado repetidas veces a lo largo de la cuarentena. Por otra parte, a nivel local, si bien el escándalo estuvo en boca de "todos", duró poco, apenas unos días, y luego todo "volvió a la normalidad". En relación con esto, Tita, una trabajadora de la salud que podríamos definir como una "informante clave", nos contaba cómo era, para ella, el típico proceso a través del cual ciertas acciones se volvían, redes sociales mediante, objeto de rumores y luego de escándalos:

13 La rápida difusión de rumores a través de las redes sociales en épocas de "hipermediatización" (CARLÓN, 2015) merecería un tratamiento aparte, así como las adaptaciones y recontextualizaciones que dichos rumores sufren al cambiar de escala. En relación con la pérdida del contexto original de los chismes difundidos más allá de sus límites locales, resulta sugestiva la reflexión de De Abrantes (2017, p. 171), según la cual "para que un chisme pueda circular, impactar, generar efectos en las representaciones colectivas e individuales de los sujetos, no se necesita de una comunidad homogénea de iguales, tampoco de un grupo social a escala reducida; lo que necesita el chisme para arraigarse y circular es que la información que lleva, corroborada o no, sea relevante, problemática, atractiva, sugerente o polémica para aquellos sujetos que forman parte de este acto social". 
“Acá se sabe si la gente se aísla": (anti)anonimato, cuidado y poder en localidades medianas... Johana Kunin • Yanina Faccio

Primero, escrache. Después, la foto empieza a circular en las redes. Y ahí, el rumor, el chisme: "salieron a tomar mate", "no se cuidaron". Y ahí es noticia cuando estalla el caso. Después, la gente continúa su rutina, queda como una cosa más en el pueblo.

En definitiva, en este apartado hemos podido observar el modo en el que comportamientos novedosamente "desviados" -tales como hacer una reunión en una pulpería, hasta hace meses una práctica inocente- terminan por ser marcados como tales a través de mecanismos ya conocidos, que van del rumor al escándalo y a las sanciones sobre la reputación, para generalmente devolverlos, al final, a la "vida normal". Así, de manera similar a lo que ocurría con el chisme, las problemáticas y dinámicas extraordinarias de la pandemia son reabsorbidas bajo mecanismos sociales ordinarios que las vuelven, de alguna manera, más ordinarias. Ahora bien, no todo es "continuidad" en tiempos de COVID. En lo que sigue, veremos que la situación pandémica ha posibilitado la emergencia de denuncias abiertas y de demandas al Estado hasta hace unos meses indecibles o impensadas.

\title{
Denunciando a los poderosos en nombre del cuidado y de la igualdad de los individuos ante la ley
}

\author{
"Producir es una cosa y hacer fiestas en cuarentena es otra." \\ Mirta (Esposa de un peón rural, quejándose sobre los patrones \\ de él por audio de WhatsApp)
}

Las localidades del tipo que estudiamos, que desde el sentido común suelen ser pensadas como espacios sociales cohesivos y menos desiguales que las grandes metrópolis, son detentoras, como se habrá podido ver hasta aquí, de un carácter conflictivo, en gran parte a causa del intenso inter-reconocimiento que existe entre sus residentes y, con ello, de su mutua vigilancia. Se trata, además, de espacios profundamente jerárquicos y patriarcales, en tanto 
“Acá se sabe si la gente se aísla": (anti)anonimato, cuidado y poder en localidades medianas... Johana Kunin • Yanina Faccio

en su seno se presentan con fuerza los roles sociales de "patrón" y de "peón", ligados al tipo de producción agraria que domina la zona desde hace más de 100 años (KUNIN, 2019; VILLULLA, 2014; VILLULLA y HADIDA, 2012). En un contexto en el que generalmente los "patrones" -es decir, los dueños y los gestores de explotaciones agroindustriales- residen, "desterritorializados", en ciudades de mayor envergadura, o "a caballo" entre dichas ciudades y el campo, la pandemia y la cuarentena obligatoria -que han sido más duras en los entornos metropolitanos- los ha motivado a "escapar" a sus dominios rurales para evitar el confinamiento obligatorio. Al mismo tiempo, desde comienzos de la cuarentena, el gobierno nacional decretó a las actividades agropecuarias como "esenciales" y, por ende, como permitidas; por esta razón, los trabajadores rurales de todos los rangos pudieron continuar con sus trabajos, a condición de que tomaran los recaudos sanitarios oficialmente establecidos.

Durante este período, nuestros informantes que se desempeñan como empleados agrarios comenzaron a confiarnos chismes por WhatsApp acerca de cómo, por ejemplo, "familias dueñas de campo se vinieron de Buenos Aires, y van y vienen los fines de semana" o sobre los grandes asados ${ }^{14}$ que se harían en estancias con invitados provenientes de otras localidades. Junto con estos relatos acerca de las idas y venidas de los patrones, nos llegaron otros más detallados acerca del modo de vida que detentaban durante el período de aislamiento. Por ejemplo, la esposa de un trabajador rural nos dijo:

\begin{abstract}
Acá hoy hasta nos impusieron, que lo impuso el Estado, que vaya uno por familia [a la ciudad cabecera de distrito] pero vinieron los patrones, se pasearon por todos lados, sin barbijo, sin hisopado, el mayordomo hoy se fue a [otro distrito] a ver a la familia y el lunes vuelve como si nada pero a los empleados de acá adentro no nos dejan traer comida [de la ciudad cabecera].
\end{abstract}

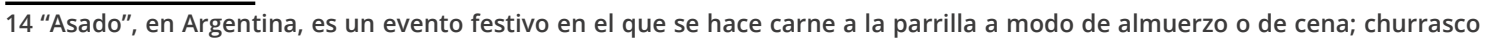
en portugués. 
“Acá se sabe si la gente se aísla": (anti)anonimato, cuidado y poder en localidades medianas... Johana Kunin • Yanina Faccio

En relación con estos comportamientos desviados de los patrones con respecto a las reglas impuestas por la cuarentena, otra mujer habitante de una localidad rural nos contaba que:

\begin{abstract}
Haytrabajadores que han querido denunciarque los patronesviolan la cuarentena. Pero están con miedo y pagan las consecuencias de mala manera: los amenazan. Ya he oído varios casos. Hay que salir urgente a decir que en el campo también cumplan la cuarentena. Producir es una cosa y hacer fiestas es otra.
\end{abstract}

En todo caso, estas perspectivas nativas -y esto lo hemos comprobado una y otra vez durante nuestro trabajo de campo- nos muestran que, en espacios sociales con prácticas de jerarquización tan acuciantes, las posibilidades de echar a correr rumores, realizar denuncias, ser objeto de rumores o de denuncias, o participante de un escándalo, dependen, en gran medida, de la jerarquía social que se ocupa. En este contexto, las conductas de "patrones" o familias poderosas y bien establecidas -en términos nativos, "familias conocidas"- suelen ser tema de chismes y rumores, pero pocas veces se ven implicadas en escándalos abiertos o denuncias. La desigualdad es difícilmente denunciada, o rumoreada muy por lo bajo. Hasta que se desata una pandemia y el nivel de control social habilitado por la situación extraordinaria se vuelve contra los patrones, a través de la movilización de "repertorios de impugnación moral" (NOEL, 2011, 2014) que identificamos como propios de estos tiempos de COVID-19.

Narraremos, a continuación, un caso ocurrido en el distrito de Azcurra. Azcurra es un partido bonaerense "conocido" porque allí reside, desde principios de siglo, la familia Dalhmann, famosa por su importancia en el mundo de los agronegocios a nivel global. Además de jugar un rol importante en la economía argentina, dicha familia suele ocupar posiciones en el gobierno municipal; actualmente, por ejemplo, el intendente azcurrense es pariente político del presidente del grupo empresario familiar "Los Dahlmann". En este contexto, en septiembre de 2020 un trabajador rural llamado Luis Rodríguez 
“Acá se sabe si la gente se aísla": (anti)anonimato, cuidado y poder en localidades medianas... Johana Kunin • Yanina Faccio

decidió denunciar a los Dalhman mediática y policialmente tras enterarse, a través de su esposa -quien trabajaba para ellos como empleada doméstica- de que sus miembros estaban festejando un cumpleaños masivo en una de sus estancias. Mientras se dirigía a hacer la denuncia en la comisaría local, Luis hizo un live por Facebook en el que, tras contar sobre la fiesta y sobre cómo había visto "autos de alta gama" -evidentemente de invitados- en las inmediaciones de la estancia, decía:

Los que me conocen ya saben quién soy. Estoy indignadísimo, acabo de llegar del campo [...] hago responsable al intendente porque si no hay para los pobres, no hay para los ricos. Acá hay una ciudad que se está mintiendo. Ya mismo me voy a ir a la comisaría a hacer la denuncia. Quiero que la ciudad me apoye en lo que voy a hacer. El derecho es para todos iguales.

Al día siguiente, la mujer de Luis fue despedida de su trabajo en represalia por su falta de discreción; la policía, por otra parte, llegó tarde al sitio indicado y no encontró a nadie, de modo tal que la denuncia no llegó a buen puerto. Esta situación, sin embargo, no hizo más que disparar la difusión del video de la acusación, que llegó a las 28 mil reproducciones -el distrito de Azcurra tiene apenas 23 mil habitantes-, 900 compartidas y 253 comentarios en Facebook, algunos de los cuales fueron los siguientes:
Siento mucha bronca $\times$ q ellos pueden festejar cumpleaños con gente de BS AS [Buenos Aires, en referencia a la capital argentina] y nosotros estamos recagados hasta las patas15 [sic].
Te felicito $\mathrm{x}$ poner lo q muchos tendríamos q poner para q estos sinvergüenzas dueños $d$ todo sean denunciados vas a tener el apoyo $\mathrm{d}$ todo un pueblo, $\mathrm{t}$ apoyamos [...] gracias $\mathrm{x}$ el valor $\mathrm{q}$ tenés vos y tu Flia. Un abrazo y fuerzas.
Muy bien señor si todos actuaran así no estaríamos tan mal, gracias por cuidar y cuidarse, y tener empatía!!!!

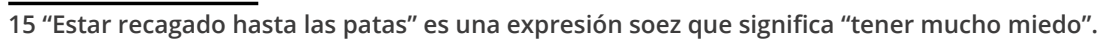


“Acá se sabe si la gente se aísla": (anti)anonimato, cuidado y poder en localidades medianas... Johana Kunin • Yanina Faccio

Callarse la boca, hacer oidos sordos. Y ver q la mayoría del pueblo hace el sacrificio del cuidado y los q tienen coronita, no? Los cuidados y la ley es para todos iguales.

Pero no quedó todo ahí. En los días subsiguientes, el partido político opositor le pidió explicaciones públicas al intendente del distrito, yerno de los dueños de la estancia. Al mismo tiempo, comenzó a circular un video donde se lo veía bailando vestido de gala en la supuesta fiesta clandestina. El hombre, visiblemente incómodo, tuvo que salir a aclarar en el parte municipal diario y oficial sobre la COVID-19 que el video difundido era del casamiento de su hija, que había tenido lugar 2 años antes. En su declaración, negó haber ido a un evento el fin de semana anterior y sentenció que "con relación a cuestiones que me exceden pedí que se aplicara la misma reglamentación que se aplica a cualquier vecino común".

Luis, el denunciante, por su parte, se alzó - como puede verse en los comentarios a su live transcriptos más arriba - como una suerte de héroe popular que llevó al escándalo y a la denuncia abiertas lo que ya se rumoreaba por lo bajo sin que llegara a hacerse público: que las reglas de la cuarentena eran más laxas para los "señoritos" que para "el pueblo" (PITT-RIVERS, 1989). En este caso, vemos que a los mecanismos ordinarios a través de los cuales se gestiona informacionalmente la pandemia -los chismes, los rumores, los escándalos- se suman prácticas extraordinarias, tales como esta denuncia abierta por parte de una persona que, dada su posición jerárquica, difícilmente hubiera decidido llevarla adelante en otro contexto que no fuera el actual. Estos rumores y denuncias nos "hablan" de una situación de desigualdad que, evidentemente, la gente comenzó a manifestar como problemática. Dicha desigualdad, sin embargo, no aparece explícitamente vinculada a la gran concentración de tierras 0 al alto margen de ganancias que detentan Los Dalhmann y demás "patrones", sino a la mayor libertad que ellos se arrogarían para llevar adelante su vida sin las restricciones sanitarias y de movilidad decretadas por los gobiernos nacional y municipal -tales como circular de manera limitada, usar 
“Acá se sabe si la gente se aísla": (anti)anonimato, cuidado y poder en localidades medianas... Johana Kunin • Yanina Faccio

barbijo o hacerse un hisopado si se llega desde otra localidad. En este sentido, consideramos que el cuidado de la salud emerge, en tiempos de pandemia, como un "repertorio de impugnación moral" (NOEL, 2011, 2014) prácticamente incontestable en tanto alcanza no solo al cuidado personal de la salud, sino también al comunitario: hacer cuarentena correctamente es una manera de garantizar que los demás no se contagien y que sus vidas corran menos riesgo. La fuerza del repertorio del cuidado -continuamente enfatizada, además, por los propios gobiernos- abre la posibilidad a que los actores sociales echen mano de él para denunciar conductas desviadas respecto de las esperadas en tiempos de cuarentena, pero también habilita a que, en el camino, se puedan expresar temas antes "indecibles" acerca de los diferenciales de poder propios de este tipo de localidad. Como decía una comentarista de Facebook que apoyaba a Luis: "Ios ricos son todos iguales, pero recuerden que todos vamos al mismo lugar el día que morimos, ahí van ricos y pobres".

Finalmente, hay que decir que la más afectada en este caso fue la familia de Luis, dado que su mujer, a modo de sanción, perdió su trabajo, mientras que los Dalhmann -de la que el intendente era parte- no sufrieron consecuencias legales. Las sanciones informales para ellos, sin embargo, sí fueron considerables: la reputación de sus miembros -antes intocables públicamente, al menos a nivel local- se vieron "escandalizadas" en boca del pueblo por semanas y registradas en internet para siempre. De esta forma, en este contexto particular, se dinamizaron los debates sociales sobre los derechos y deberes "para pobres y para ricos", en un distrito conocido por el manejo monopólico de los agronegocios en manos de una sola familia -la que festejaba.

Para cerrar, quisiéramos destacar un punto que emerge de los chismes que transcribíamos al inicio de este apartado, de la denuncia de Luis y de los comentarios a su video, que es la movilización de un repertorio de impugnación moral ligado no solo al "cuidado", sino también a la igualdad de los individuos ante la ley. En la introducción del artículo, mostrábamos nuestra 
“Acá se sabe si la gente se aísla": (anti)anonimato, cuidado y poder en localidades medianas... Johana Kunin • Yanina Faccio

coincidencia con Prado (1998) en lo tocante a sus constataciones acerca de que, en el pequeño y mediano urbano, las nociones "personalizantes" y relacionales de persona eran dominantes por sobre las "individuantes". Quisiéramos volver aquí sobre este tema, que, bajo otro formato, hará aparición en el apartado que sigue.

En su célebre trabajo acerca de la India, Dumont (1970), con inspiración maussiana, sostiene que la noción de "individuo" no es universal sino una concepción de persona histórica y situada, propia de la cultura occidental y moderna con sus atributos instauradores de libertad e igualdad. Posteriormente, DaMatta (1985, 2002) -a quien Prado (1998) retoma- juega sobre esta distinción, proponiendo que en Brasil coexisten en una tensión irresuelta, por un lado, entre un régimen holista y por lo tanto jerárquico y relacional, $y$, por otro, un régimen individuo-centrado propio de las "sociedades modernas", según el cual todos los individuos serían iguales ante la ley burocrática del Estado, que no haría diferencias entre ciudadanos. Discutiendo con estos autores, Goldman (1996, p. 104, nuestra traducción), por su parte, hace un llamamiento a correr el foco del holismo o el individualismo entendidos como "tipos sociales" y propone, en relación con la noción de "persona", hacer una "análisis de los procesos inmanentes a múltiples prácticas", es decir, encontrarla en las acciones de los propios actores sociales, más allá de las esencias pre-establecidas.

Aquí, elegimos movilizar las categorías de "individuo" y "persona" en un "sentido operativo y metodológico" (GOLDMAN, 1996, p. 103, nuestra traducción), en tanto permiten echar luz sobre los fenómenos empíricos que estamos presenciando. Por un lado, en los casos que hemos visto, los encuadramientos "personalizantes" de los actores sociales son evidentes: ni siquiera los gobiernos estatales, en localidades como Azcurra, están conformados por "individuos" sino por "personas" de las que se sabe a qué familia pertenecen y en qué jerarquía se ubican. Por otro, y esto se constituye como un emergente propio de estos tiempos de pandemia, en las elocuciones de nuestros interlocutores vemos que la dimensión moderna y democratizante de "individuo" 
“Acá se sabe si la gente se aísla": (anti)anonimato, cuidado y poder en localidades medianas... Johana Kunin • Yanina Faccio

aparece movilizada, junto con la de "cuidado", como repertorio de impugnación moral para clamar que -retomando las categorías de una de las comentaristas de Facebook antes citada- tanto "ricos" como "pobres" deberían ser iguales ante las duras e inéditas reglas de la cuarentena.

\title{
¿La estatización del rumor? Auto-denuncias y demandas de anti-anonimato
}

\author{
"Si en algún momento contraigo COVID, Dios quiera que no, voy a \\ publicar mi nombre." \\ Declaración en Facebook de mujer residente en Azcurra
}

A esta altura del artículo, habrá quedado en evidencia para el lector que el nivel de activación de mecanismos ordinarios de control social-el chisme, el rumor, el escándalo o la denuncia- han proliferado durante los tiempos extraordinarios de la pandemia, dando pie, incluso, a la realización de acusaciones públicas extraordinarias como la que hemos relatado en el apartado anterior. En este contexto, quiénes hacen cuarentena y quiénes no, cómo la hacen y cuáles son sus contactos estrechos son temas de dominio público, y se mantienen más o menos discretos según el caso. También lo es la identidad de los supuestos contagiados, tal como se evidenciaba en las listas y los audios de WhatsApp que presentábamos en el apartado inicial de nuestra argumentación.

En relación con esto, hemos sabido de casos extremos, como el de una persona sintomática que se había hisopado en el hospital de su pueblo y que se enteró de que el resultado era positivo a través de la radio y no de vías hospitalarias. En mayo de 2020, en Facebook, la afectada se quejaba de la siguiente manera:

Todas estas circunstancias, y en una ciudad como la nuestra, en la que algunos vecinos se alimentan con el Morbo y con chusmerios ${ }^{16}$, que solo dañan y perjudican nuestra integridad

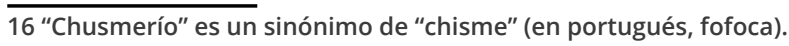


"Acá se sabe si la gente se aísla": (anti)anonimato, cuidado y poder en localidades medianas... Johana Kunin - Yanina Faccio

emocional, la de mis hijas, y la de toda mi familia. Publicando y haciendo circular fotos con mis hijas menores de edad. Les Parece Bien???? Qué pasa si te pasa a vos y tu familia?, si les pasa a tus hijos o a tus padres?

En línea con estas expresiones de indignación, a continuación, reproducimos otra declaración en la misma red social. En ella, acompañando la foto de una enfermera con su traje de seguridad sanitaria blanco, su barbijo y su máscara de acrílico transparente, se puede leer lo siguiente:

Si soy COVID 19 POSITIVO.!! Les pido q no divulguen palabras q lastiman no a MI. Si no a mi seres queridos q los tengo lejos y no veo ya hace más de 7 meses. Estoy cursando el virus controlada por la Dra. [nombre de la médica] a diario $x$ el comité de crisis. [Estoy] ESTABLE PASANDO X TODOS LOS SÍNTOMAS Q TIENE ÉSTE VIRUS... PERO BIEN... ESTABLE!! BASTA DE DECIR COSAS Q NO SON VERDAD!! GRACIAS!!

\section{8}

En ambas citas, vemos cómo personas infectadas narran agentiva y activamente su propia historia, procurando dejar de ser meros objetos pasivos de chismes y rumores; podríamos decir que, al auto-denunciarse abiertamente, deciden ahorrarse las instancias de "control social discreto" que hemos expuesto a lo largo de este artículo. Las expresiones de indignación -observables en el vocabulario y en el prolífico uso de mayúsculas- y la cantidad de mensajes similares que hemos encontrado en las últimas semanas dan cuenta de que, con el aumento de los contagios, también ha aumentado la intensidad del control social entre los co-residentes de estas localidades (Figura 2). 
"Acá se sabe si la gente se aísla": (anti)anonimato, cuidado y poder en localidades medianas... Johana Kunin • Yanina Faccio

Figura 2. Meme del sitio de IG "Es de provinciano" que circuló en las redes de nuestros interlocutores durante la pandemia

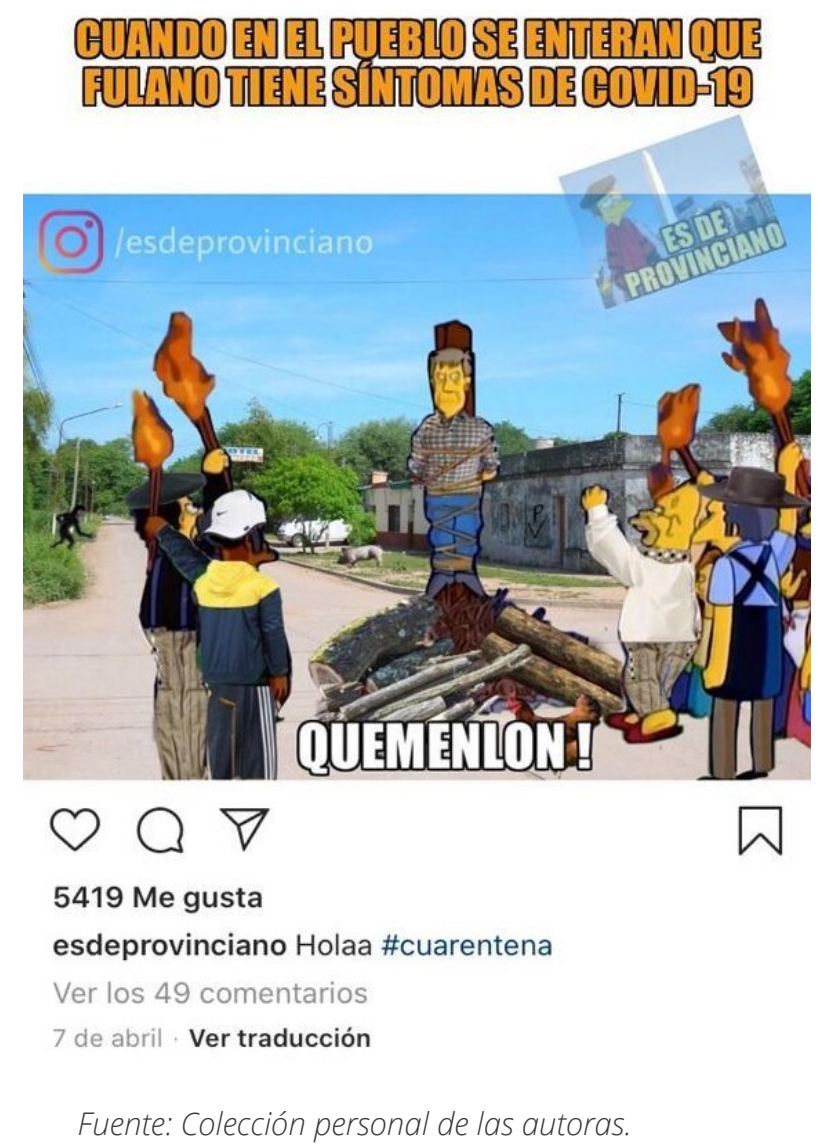

De alguna manera en línea con declaraciones como estas, hemos observado que incluso personas que no padecen el virus manifiestan que, de hacerlo, también se auto-denunciarían, como puede verse en la siguiente alocución que una mujer de mediana edad hizo también en Facebook:

Si en algún momento contraigo COVID, dios quiera que no, voy a publicar mi nombre, para que puedan identificarse si estuvieron en contacto conmigo. No es un delito contraer el virus, pero sí es una obligación evitar que se propague.

En este comentario, los deberes o las obligaciones hacia los demás, característicos de las vinculaciones jerárquico-relacionales 
“Acá se sabe si la gente se aísla": (anti)anonimato, cuidado y poder en localidades medianas... Johana Kunin • Yanina Faccio

que impregnan estas localidades "donde todos se conocen", quedan traducidas al repertorio del "cuidado comunitario" -sobre el cual nos hemos explayado en el apartado anterior. En vistas a "cuidar la salud", se propone reforzar el carácter "anti-anónimo" que ya era propio de estos medios sociales desde tiempos previos al COVID-19. Así, nombrarse y nombrar a los demás como contagiados parecen configurarse como una forma folk de gestionar la pandemia y cuidar la salud y la proliferación de la enfermedad. En línea con la propuesta de la mujer recién citada, un vecino de uno de los distritos en los que trabajamos presentó en un medio de comunicación local una propuesta para que el gobierno municipal divulgara las zonas de residencia de los infectados, lo cual, en un contexto urbano de este tipo, sería prácticamente lo mismo que dar nombres, apellidos y señas personales:

La sugerencia es diagramar un mapa que muestre las zonas donde hay personas afectadas por el COVID-19. Se alerta a la población en qué lugares hay que tener más cuidado. Entiendo que todos juntos con la información que se nos proporcione y con responsabilidad podemos pasar esta pandemia, unidos y salvar vidas al tiempo de evitar contactos de riesgo.

En la apertura de este artículo, mostrábamos cómo, día a día, los gobiernos municipales informaban sobre el estado de la pandemia a nivel local desde una lógica burocrática y oficial, en la que los contagiados, muertos y recuperados eran presentados como "individuos" (DAMATTA, 1985, 2002) abstractos y anónimos, pasibles de ser contabilizados bajo la forma de cifra. Los números aseguraban, por un lado, la circulación clara de la información y, a la vez, su discreción. Sin embargo, en los últimos tiempos, hemos visto que -en línea con la demanda de un mapeo de los infectados- las personas comentan las discretas publicaciones de la Municipalidad exigiendo los nombres que se esconden detrás de las cifras. 
“Acá se sabe si la gente se aísla": (anti)anonimato, cuidado y poder en localidades medianas... Johana Kunin • Yanina Faccio

Y aquí hay un punto sobre el que quisiéramos llamar la atención. Si la categoría de "individuo" anónimo e igual ante la ley era, en el apartado anterior, movilizada para denunciar tratos jerárquicos y desiguales -propios de estos contextos en los que la noción relacional de persona es dominante-, en los casos que aquí tratamos, los pobladores estarían demandándole al Estado que, por el contrario, "desanonimizara" sus informes oficiales y se ocupara de difundir datos personales, identificando a los enfermos de una localidad en la que "todo el mundo" sabe dónde vive cada quién y en qué red relacional se inserta. Es decir, que lo que se estaría pidiendo es que las comunicaciones del gobierno municipal salieran de la lógica del "individuo" para controlar una cadena de chismes en continua proliferación. Se estaría proponiendo, en definitiva, que, en nombre del cuidado comunitario de la salud, de alguna manera, se "estatizara" el rumor, sacándolo de la boca del "pueblo" y, de alguna manera, neutralizándolo a través de su burocratización -posiblemente para contrarrestar la alta conflictividad en torno al tema. Es evidente que, en épocas de pandemia, el cuidado de la salud es una preocupación bien real. Sin embargo, este no deja de ser, al mismo tiempo, un repertorio movilizado en vistas a cuidar otro bien igual de importante: el de las reputaciones personales continuamente puestas en cuestión por la cuarentena y los contagios.

\section{Reflexiones finales}

A lo largo de este artículo, hemos intentando mostrar, a través de la reconstrucción de escenas etnográficas significativas, los modos en los que la pandemia se ha gestionado en localidades pequeñas y medianas de la provincia de Buenos Aires en las que dominan tramas sociales intensamente personales. Aquí hemos considerado que la circulación de información -a través de distintas vías, más o menos oficiales- ha sido un modo de gestionar la pandemia, en el sentido de que ha provisto de un marco para, por 
“Acá se sabe si la gente se aísla": (anti)anonimato, cuidado y poder en localidades medianas... Johana Kunin • Yanina Faccio

un lado, encuadrar una situación inédita bajo formatos conocidos $y$, por otro, controlar el comportamiento de sus habitantes en cuarentena. En este contexto, los chismes, rumores y escándalos han tendido a normalizar y a volver ordinaria una situación a todas luces extraordinaria.

Por otra parte, precisamente a causa de este carácter extraordinario, hemos observado la emergencia de ciertos fenómenos que se configuran, a la luz de nuestras experiencias etnográficas previas, como novedosos. La alta proliferación de rumores y denuncias en pro del cuidado comunitario ha posibilitado que quienes antes no eran, por su posición de poder, públicamente denunciables, ahora también hayan podido serlo. Además, hemos observado el surgimiento de la demanda inédita de que el Estado se haga cargo de "tener la última palabra" en cuanto a la circulación de información acerca de los infectados por COVID-19, de modo tal que el "individuo anónimo e igual ante la ley" -que posiblemente no exista sino en la abstracción (SEMÁN, 2001) de las comunicaciones oficiales- refleje aristas más "personales". Finalmente, la importancia de las redes sociales, que se habrá podido reconocer a lo largo de todo el artículo, merece una mención aparte; creemos que la reflexión en torno al rol de estas nuevas instancias mediáticas en el marco de sociabilidades situadas podría ser abordada de manera específica en futuros estudios. Acerca de ellas, ahora podemos decir que las redes sociales ya formaban parte importante de nuestros campos en épocas previas a la pandemia, pero que recién ahora, como emergente de esta situación extraordinaria, logramos entender la relevancia etnográfica de los dinámicos y complejos vínculos online y offline en este tipo de localidades donde se intersectan de manera diferencial, parcial y simultánea prácticas múltiples vinculadas con nociones de persona relacionales e individuocentradas.

Para cerrar, quisiéramos sugerir que un primer paso a la hora de evaluar los impactos pandémicos sobre nuestros grupos de estudio es desconfiar de la fantasía de su "extrema novedad". Si bien 
“Acá se sabe si la gente se aísla": (anti)anonimato, cuidado y poder en localidades medianas... Johana Kunin • Yanina Faccio

la pandemia es, claramente, una situación inédita, los mecanismos que se ponen en juego para lidiar con ella suelen ser los que "se tienen a mano", es decir, los ordinarios. En este punto, recordamos el modelo de cambio social que propone Sahlins (1981), según el cual los sistemas sociales se configuran como estructuras de posiciones histórica y socialmente construidas y que, por lo tanto, se encuentran sujetas a permanentes re-evaluaciones ante la dinámica específica de cada coyuntura práctica. En otros términos, no hay continuidad social sin alteración ni alteración sin continuidad (SAHLINS, 1981). En este sentido, algunos de los repertorios y prácticas que hemos destacado -la conversión de personas locales en personajes de fábulas moralizantes nacionales, las apelaciones a la "igualdad de los individuos ante la ley" para denunciar a los patrones que no hacen cuarentena, los pedidos de que el Estado "estatice" el rumor y "personalice" sus informes, etc.- se configuran, a nuestro juicio, como emergentes propios de estas épocas, pero que a la vez no dejan de montarse sobre modalidades previas.

No todo, entonces, es novedad en los nuevos tiempos de la COVID-19. Por ello, posiblemente, el mejor comienzo para dilucidar los impactos pandémicos sobre nuestros grupos sociales de interés implique traer concienzudamente a escena lo que ya conocíamos de su vida ordinaria previa. Así, incluso, tal vez la pandemia nos permita ver fenómenos que ya estaban ahí-como, en nuestro caso particular, el de las redes sociales- pero que nunca habían captado nuestra atención a nivel reflexivo. En todo caso, confiamos en que no queda sino atender a las temporalidades propias de nuestros campos etnográficos, a sus órdenes cotidianos y a las rupturas de esos órdenes, para comenzar a atisbar cuáles son los emergentes extraordinarios propios de los tiempos sin duda extraordinarios que actualmente vivimos. 
“Acá se sabe si la gente se aísla": (anti)anonimato, cuidado y poder en localidades medianas... Johana Kunin • Yanina Faccio

\section{Agradecimientos}

Quisiéramos agradecer al Dr. Nicolás Viotti, colega que atentamente compartió con nosotras perspectivas teóricas y bibliográficas para pensar algunos de los ejes del presente artículo. También, a nuestras colegas "sobre el terreno", las licenciadas Ana del Cielo Amado, Paula Yacovino y Lucía Blasco, que con gran generosidad compartieron con nosotras materiales circulantes en sus ciudades y agudas observaciones acerca de la situación que allí se está viviendo a raíz de la pandemia. Finalmente, a nuestros interlocutores de las distintas localidades de la provincia de Buenos Aires que aquí abordamos, quienes, con paciencia y atención, respondieron a nuestras muchas preguntas e inquietudes, aún a la distancia.

\section{Referencias}

\section{4}

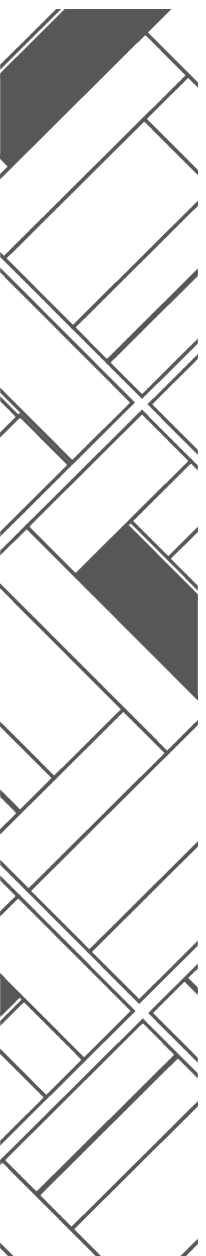

ABRAMOWITZ, Sharon. Ten things that anthropologists can do to fight the West African Ebola epidemic. 26 sep. 2014. Disponible en: http://somatosphere.net/2014/ten-things-thatanthropologists-can-do-to-fight-the-west-african-ebola-epidemic. html/. Acceso: 1 oct. 2020.

ALBALADEJO, Christophe. Dinámica de la inserción territorial de la agricultura pampeana y emergencia del agribusiness. In: GRAS, Carla; HERNÁNDEZ, Valeria (comp.). El agro como negocio: producción, sociedad y territorios en la globalización. Buenos Aires: Biblos, 2013. p. 67-96.

ALI, Inayat. The COVID-19 pandemic: making sense of rumor and fear. Medical Anthropology, London, v. 39, n. 5, p. 376-379, 2020.

ARGENTINA. Decreto No. 408, de 26 de abril de 2020. Prorroga el aislamiento social, preventivo y obligatorio. 26 abr. 2020. 
"Acá se sabe si la gente se aísla": (anti)anonimato, cuidado y poder en localidades medianas... Johana Kunin - Yanina Faccio

Disponible en: https://www.boletinoficial.gob.ar/detalleAviso/primera/228261/20200426. Acceso: 9 oct. 2020.

BENSON, Matthew. COVID-19 rumours as transcripts of resistance in South Sudan. 18 jun. 2020. Disponible en: https://www.csrf-southsudan.org/covid19/covid-19-rumours-astranscripts-of-resistance-in-south-sudan/. Acceso: 1 oct. 2020.

BLANC, Manuela. "Para além das suas fronteiras": pessoalidade, conduta pública e trajetórias pequeno-urbanas. Revista Brasileira de Sociologia da Emoção, João Pessoa, v. 15, n. 45, p. 96-111, 2016.

BRIGGS, Charles. Communicability, racial discourse, and disease. Annual Review of Anthropology, Palo Alto, v. 34, n. 1, p. 269291, 2005.

CARLÓN, Mario. Registrar, subir compartir. Prácticas fotográficas en la era contemporánea. In: SIMPOSIO INTERNACIONAL DE ESTÉTICA, 5., 2015, Santiago de Chile. Actas [...]. Santiago de Chile: Pontificia Universidad Católica, 2015. p. 31-54.

DAHL, Bianca. Beyond the blame paradigm: rethinking witchcraft gossip and stigma around HIV-positive children in Southeastern Botswana. African Historical Review, London, v. 44, n. 1, p. 5379, 2012.

DAMATTA, Roberto. A casa e a rua. São Paulo: Brasiliense, 1985. DAMATTA, Roberto. Carnavales, malandros y héroes. Hacia una sociología del dilema brasileño. México, DC: FCE, 2002.

DE ABRANTES, Lucía. Habitar entre polos. Una etnografía de las experiencias de transformación urbana en una ciudad media bonaerense. Director: Gabriel Noel. 2017. Tesis (Maestría en Antropología Social) - Facultad Latinoamericana de Ciencias Sociales, Buenos Aires, 2017.

DINIZ, Debora. Zika: do sertão nordestino à ameaça global. Rio de Janeiro: Civilização Brasileira, 2016. 
"Acá se sabe si la gente se aísla": (anti)anonimato, cuidado y poder en localidades medianas... Johana Kunin - Yanina Faccio

DUMONT, Louis. Homo hierarchicus. El sistema de castas y sus implicaciones. Madrid: Aguilar, 1970.

ELIAS, Norbert; SCOTSON, John L. Os estabelecidos e os outsiders. Rio de Janeiro: Jorge Zahar, 2000.

FELDMAN-SAVELSBERG, Pamela; NDONKO, Flavien; YANG, Song. How rumor begets rumor: collective memory, ethnic conflict and reproductive rumors in Cameroon. In: FINE, Gary Allan; CAMPIONVINCENT, Veronique; HEATH, Chip (org.). Rumor mills. London: Routledge, 2017. p. 141-158.

FONSECA, Cláudia. Família, fofoca e honra. Porto Alegre: Ed. UFRGS, 2000.

GILMAN, Sander. Seeing the AIDS patient. In: GILMAN, Sander. Disease and representation: images of illness from madness to AIDS. Ithaca, NY: Cornell University Press, 1991. p. 245-272.

GLUCKMAN, Max. Gossip and scandal. Current Anthropology, Chicago, v. 4, n. 3, p. 307-316, 1963.

GOLDMAN, Márcio. Uma categoria do pensamento antropológico: a noção de pessoa. Revista de Antropologia, São Paulo, v. 39, n. 1, p. 83-109, 1996.

HAGENE, Turid. Prácticas políticas cotidianas en un pueblo originario del Distrito Federal: el papel de los chismes y los rumores. Nueva Antropología, México, v. 23, n. 73, p. 35-57, 2010.

KOURY, Mauro Guilherme Pinheiro; BARBOSA, Raoni Borges. Cultura emotiva e moralidade em pequenas cidades: uma análise etnográfica do papel da fofoca em sociabilidades urbanas de pequena escala. Revista Brasileira de Sociologia da Emoção, João Pessoa, v. 1, n. 1, p. 21-40, 2017.

KUNIN, Johana. El poder del cuidado: mujeres y agencia en la pampa sojera argentina. Directores: Irene Bellier y Alejandro Grimson. 2019. 388 h. Tesis (Doctorado en Antropología) Universidad Nacional de San Martín, Buenos Aires, 2019. 
"Acá se sabe si la gente se aísla": (anti)anonimato, cuidado y poder en localidades medianas... Johana Kunin • Yanina Faccio

KUNJANA, Rahardi. COVID-19 hoaxes in virtual media: perlocutionary effects in cyber-pragmatic perspective. International Journal of Advanced Science and Technology, Hobart, v. 29, n. 5, p. 11678-11688, 2020.

KUTALEK, Ruth et al. Ebola interventions: listen to communities. The Lancet Global Health, London, v. 3, n. 3, e131, 2015. MARTINEAU, Fred; WILKINSON, Annie; PARKER, Melissa. Epistemologies of Ebola: reflections on the experience of the Ebola response anthropology platform. Anthropological Quarterly, Baltimore, v. 90, n. 2, p. 475-494, 2017.

MERRY, Sally Eagle. Rethinking gossip and scandal. In: KLEIN, D. B. (org.). Reputation: studies in the voluntary elicitation of good conduct. Ann Arbor, MI: University of Michigan Press, 1997. p. 47-80.

NIEHAUS, Isak; JONSSON, Gunvor. Dr. Wouter Basson, Americans, and wild beasts: men's conspiracy theories of HIVIAIDS in the South African Lowveld. Medical Anthropology, London, v. 24, n. 2, p. 179-208, 2005.

NOEL, Gabriel. Cuestiones disputadas. Repertorios morales y procesos de delimitación de una comunidad imaginada en la costa atlántica bonaerense. Publicar en Antropología y Ciencias Sociales, Buenos Aires, n. 11, p. 99-126, 2011.

NOEL, Gabriel. La autoctonía como garantía moral de la política: retóricas de la legitimidad en una ciudad intermedia de la provincia de Buenos Aires (Argentina). Papeles de Trabajo, Buenos Aires, v. 8, n. 13, p. 54-76, 2014.

PAINE, Robert. What is gossip about? An alternative hypothesis. Man, New Series, v. 2, n. 2, p. 278-285, 1967.

PARKER, Richard. Sexuality, culture, and power in HIV/AIDS research. Annual Review of Anthropology, Palo Alto, v. 30, n. 1, p. 163-179, 2001. 
"Acá se sabe si la gente se aísla": (anti)anonimato, cuidado y poder en localidades medianas... Johana Kunin - Yanina Faccio

PELLEGRINO, Manuela. COVID-19: the 'invisible enemy' and contingent racism -reflections of an Italian anthropologist conducting fieldwork in Greece. Anthropology Today, London, v. 36, n. 3, p. 19-21, 2020.

PITT-RIVERS, Julian. Un pueblo de la sierra: Grazalema. Madrid: Alianza, 1989.

PIZARRO, Matías; MATTA, Juan Pablo. Las relaciones vecinales como clave analítica de ciertas violencias asociadas al COVID-19 en la Argentina. Dilemas: Revista de Estudos de Conflito e Controle Social, Rio de Janeiro, p. 1-10, 2020. Reflexões na Pandemia 2020. Disponible en: https://www.reflexpandemia.org/ texto-63. Acceso: 9 oct. 2020.

PRADO, Rosane. Cidade pequena: paraíso e inferno da pessoalidade. Cadernos de Antropologia e Imagem, Rio de Janeiro, n. 4, p. 31-57, 1998.

RENNE, Elisha. The politics of polio in Northern Nigeria. Bloomington, IN: Indiana University Press, 2010.

ROOT, Robin. Situating experiences of HIV-related stigma in Swaziland. Global Public Health, London, v. 5, n. 5, p. 523-538, 2010.

SAADAT, Seyed Hassan et al. Fear and panic of COVID-19. International Journal of Travel Medicine and Global Health, Tehran, v. 8, n. 3, p. 91-92, 2020.

SAHLINS, Marshall. Historical metaphors and mythical realities: structure in the early history of the Sandwich Islands Kingdom. Ann Arbor, MI: University of Michigan Press, 1981.

SCHOEPF, Brooke. International AIDS research in anthropology: taking a critical perspective on the crisis. Annual Review of Anthropology, Palo Alto, v. 30, p. 335-361, 2001.

SEMÁN, Pablo. Cosmológica, holista y relacional: una corriente de la religiosidad popular contemporánea. Ciencias Sociales y Religión, Porto Alegre, v. 3, n. 3, p. 45-74, 2001. 
"Acá se sabe si la gente se aísla": (anti)anonimato, cuidado y poder en localidades medianas... Johana Kunin • Yanina Faccio

STADLER, Jonathan. Rumor, gossip and blame: implications for HIV/AIDS prevention in the South African lowveld. AIDS Education and Prevention, New York, v. 15, n. 4, p. 357-368, 2003. Special issue.

STALCUP, Megan. The invention of infodemics: on the outbreak of Zika and rumors. 16 mar. 2020. Disponible en: http:// somatosphere.net/2020/infodemics-zika.html/. Acceso: 1 oct. 2020.

SUBEDI, Prativa; THAPA, Bibechan; PANDEY, Aakriti. Use of social media among intern doctors in regards to COVID-19. Europasian Journal of Medical Sciences, v. 2, n. 1, p. 56-64, 2020.

VENABLES, Emilie; PELLECCHIA, Umberto. Engaging anthropology in an Ebola outbreak. Anthropology in Action, Brooklyn, v. 24, n. 2, p. 1-8, 2017.

VILLULLA, Juan Manuel. Almanaques sí, relojes no. La prolongación de la jornada laboral en la agricultura pampeana, de la última dictadura al "boom" sojero. Sociohistórica, Buenos Aires, n. 34, 2014.

VILLULLA, Juan Manuel; HADIDA, Florencia. Salto tecnológico, tiempos de trabajo y puestos laborales en la agricultura pampeana, 1970-2010. Documentos del CIEA, Buenos Aires, n. 8, p. 115-128, 2012.

VISACOVSKY, Sergio. Futuros en el presente. Los estudios antropológicos de las situaciones de incertidumbre y esperanza. Publicar, Buenos Aires, v. 16, n. 26, p. 6-25, 2019.

VISACOVSKY, Sergio. COVID-19: crisis, incertidumbre y normalidad en sectores medios del AMBA. 17 jul. 2020. Disponible en: https://www.noticiasargentinas.com.ar/crisis/covid-19-incertidumbre-y-normalidad-sectores-medios-del-amba-n88542. Acceso: 1 oct. 2020. 